\title{
TERAPAN MODEL PSYCHOLOGICAL FIRST AID (PFA) PADA PENGUNGSI BANJIR PAYA TUMPI TAKENGON, PROVINSI ACEH
}

\author{
APPLICATION OF THE PSYCHOLOGICAL FIRST AID (PFA) MODEL \\ ON FLOOD REFUGEES IN PAYA TUMPI TAKENGON, ACEH PROVINCE
}

\author{
Safuwan Amin*, Nur Afni Safarina, Yara Andita Anastasya, Ika Amalia \\ Program Studi Psikologi, Fakultas Kedokteran, Universitas Malikussaleh \\ *Email:safuwan@unimal.ac.id
}

(Diterima 25-08-2021; Disetujui 15-09-2021)

\begin{abstract}
ABSTRAK
Berbagai peristiwa/kejadian yang menjadi sumber krisis psikologis individu/kelompok, seperti bencana alam, kekerasan, bulliying, dsb. Objektif kegiatan pengabdian ini sebagai salah satu upaya pemberian pertolongan pertama psikologis (PFA) pada warga terdampak banjir Takengan, Aceh Tengah terfokus pada aspek; mengurangi keterpurukan mental, menguatkan self healing dan membangun harapan hidup. Sasaran utama kegiatan ini adalah para wanita paruh baya, anak usia sekolah dan lansia. Implementasi kegiatan diatur dalam dua sesi, yaitu 1) tahap survei dan identifikasi, dan 2) tahap evaluasi dan makna program PFA bagi warga terdampak banjir. Hasil kegiatan menunjukkan terapan model FPA pada kondisi darurat (pasca bencana) mendapat dukungan positif dari warga pengungsian banjir Takengon. Hal itu diketahui setelah sesi lanjutan (tahap II) yang dilakukan dalam rentang waktu 3,5 bulan ke depan, dimana ekspresi verbal warga dalam suasana bahagia dan penuh harapan.
\end{abstract}

Kata kunci: Terapan PFA, Warga Terdampak banjir, Takengon, Provinsi Aceh

\begin{abstract}
Various events become the source of individual/community psychological crises, such as natural disasters, violence, bullying, etc. This service activity aims to provide Psychological First Aid (PFA) to flood-affected residents in Takengon, Aceh Tengah, Aceh Province with a focus on aspects; reduce mental difficulties, strengthen self-healing and build life expectancy. The main targets of this activity are middle-aged women, school-age children, and the elderly. The implementation of activities is arranged in two sessions, namely 1) the survey and identification stage, 2) the evaluation stage and the meaning of the PFA program for floodaffected residents. The results showed that the application of the FPA model in an emergency (post-disaster) situation received positive support from residents in evacuating the Takengon flood. This was revealed after the follow-up session (stage II) which was carried out for the next 3.5 months, in which the residents' verbal expression was in a happy and hopeful atmosphere.
\end{abstract}

Keywords: PFA Model, Flood-Affected Residents, Paya Tumpi, Takengon, Aceh Province

\section{PENDAHULUAN}

Realitas kehidupan pada hakikatnya banyak rintangan dan tidak ada yang berjalan mulus seperti keinginan manusia. Ada beragam kejadian (peristiwa) yang menjadi sumber krisis dan trauma di kehidupan individu/masyarakat tanpa diundang seperti bencana alam, perang, kerusuhan sosial, kebakaran, atau kekerasaan interpersonal (kekerasan seksual, bullying, dsb). Merunut fenomena ini, orang atau kelompok orang (mungkin) kehilangan berbagai hal yang berharga dalam hidupnya; tempat tinggal, orang-orang yang dicintainya, kehormatan privasinya hingga kematian, dsb (Yuwanto, dkk. 2014). Sementara implikasi dari beragam peristiwa tersebut tentu memengaruhi realitas psikologis individu/kelompok yang terdeteksi sebagai krisis (trauma), seperti keterpurukan mental, sulit berkembang 
aspek kognitif, afektif dan bahkan konatif lantaran orang/kelompok terngiang-ngiang dengan kejadian yang dialaminya. Banyak orang mungkin merasa kewalahan, bingung, atau tidak mampu memahami apa yang sedang terjadi. Mereka dapat merasa sangat takut, cemas berlebihan, atau terus dihinggapi rasa khawatir sehingga sulit melepaskan diri dari situasi dan kondisi buruk yang dihadapinya (Yuwanto, dkk. 2014).

Berangkat dari fenomena empirik ini, logika jangka pendek (atas nama kemanusiaan) memerlukan penanganan cepat, pertolongan awal dan deteksi dini akan kemungkinan terjadinya krisis (trauma) yang lebih parah (berlanjut) pada ranah psikologis. Karena itu, program aksi tanggap darurat (diarahkan atau tidak) pasca bencana penting dilakukan pada individu atau masyarakat terdampak musibah sebagai bentuk kepedulian sosial bagi mereka yang sedang merasakan kondisi buruk di kehidupannya.

Dari sudut pandang psikologi, pertolongan pertama psikologis (Psychological First Aid) merupakan respons manusiawi dan suportif (gerakan hati nurani) pada sesama yang sedang menderita; bukan hanya fisik saja, namun juga tekanan mental dan memerlukan dukungan psikologis. (IASC, 2007; Sphere, 2011, dalam Margaretha \& Dita Kencana Sari, 2020). PFA disinyalir sebagai keterampilan pekerja kemanusiaan yang bertujuan untuk mengurangi dampak negatif seperti stress, depresi, frustasi, dsb., dalam rangka pencegahan gangguan kesehatan mental yang lebih buruk akibat situasli krisis (Al Hamidy, 2020).

Peristiwa banjir bandang di dataran tinggi Gayo, Aceh Tengah, Provinsi Aceh yang terjadi pada petang hari (13-14/5/2020) menjelang maghrib memberi kejutan mental pada masyarakat setempat. Realitas itu belum pernah dirasakan warga setempat sebelumnya hujan deras disertai banjir dan tanah longsor dari atas pengunungan. Menurut informasi warga, "kawasan ini memang parah kali, walau tidak ada korban jiwa dalam banjir ini, tapi tempat tinggal warga hancur porak-poranda, dan ada yang dibawa banjir" (Informasi M. Husen 45th, 16/05/2020).

Hasil survei umum tim PKM psikologi Universitas Malikussaleh (Psikologi Unimal) pasca bencana di lokasi bekas banjir Takengon pada medio 16 Mei 2020, banjir menghantam 4 desa di Kecamatan Kebayakan, Takengon Aceh Tengah, yang terparah adalah di Desa Paya Tumpi. Adapun semua warga terdampak banjir (pengungsi) yang diamankan di Gedung SDN 13 Kebayakan (posko pengungsian warga) memang memerlukan bantuan/pertolongan dalam aspek medis, psikologis dan material lainnya; sembako dan tempat pengungsian yang aman (Hasil investigasi, 16/05/2020).

Atas dasar realita situasi demikian, tim PKM Psikologi Universitas Malikussaleh (Unimal) Lhokseumawe bersepakat untuk memberi bantuan psikologis secara suka rela 
yang tergabung dalam Universitas Malikussaleh Peduli Banjir Takengon (terdiri atas tim pembersihan lingkungan fisik, tim bantuan material dan sembako, dan tim pemulihan kesehatan mental warga terdampak banjir/tim dosen psikologi, dimana ke semua tim itu dibantu oleh sejumlah mahasiswa dari berbagai jurusan yang ada) pada 16/5/2020.

\section{BAHAN DAN METODE}

Kegiatan pengabdian ini bertujuan untuk membantu pemulihan kesehatan mental (psikologis) warga terdampak bencana banjir bandang di Desa Paya Tumpi, Takengon Aceh Tengah, Provinsi Aceh medio Mei 2020. Secara spesifik kegiatan pengabdian ini menerapkan model Psychological First Aid (PFA), yaitu berusaha memberi pertolongan dalam aspek; mengurangi keterpurukan mental lanjutan, menguatkan self-healing dan membangun harapan hidup ke depan pada warga pengungsian banjir bandang Takengon. Adapun sasaran program aksi tanggap darurat model PFA ini adalah kaum ibu, anak usia sekolah/TK dan lansia.

Adapun metode pelaksanaan dirancang dalam dua sesi kegiatan operasional, yaitu: 1) tahap survey umum dan identifikasi terapan pemberian bantuan psikologis yang diperlukan. Tahap ini dilakukan pada tanggal 16/05/2020; dan 2) tahapan evaluasi umum dan interpretasi ketepatan terapan model PFA dilakukan 3,5 bulan kemudian pada tanggal 14-15/09/2020, sebagai tindak lanjut kegiatan untuk melihat kebermaknaan program kegiatan yang telah dilaksanakan sebelumnya melalui teknik FGD di lokasi eks banjir Takengon.

\section{HASIL DAN PEMBAHASAN}

\section{Rasionalitas Kegiatan}

Pelaksanaan kegiatan pengabdian masyarakat ini dilakukan oleh tim dosen bersama mahasiswa Psikologi Unimal setelah terjadi banjir di Desa Paya Tumpi, Kecamatan Kebayakan, Takengon - Aceh Tengah, Provinsi Aceh. Hasil investigasi lapangan memberi informasi bahwa kondisi permukiman penduduk (eks lokasi banjir) itu terletak persis di tikungan berkelok yang merupakan pintu gerbang masuk ke kota Takengon. Kawasan desa Paya Tumpi ini terletak persis di pinggir pengunungan kabayakan yang merupakan daerah padat lalu lintas dari dan ke Takengon. Lantaran hujan deras 2 hari 2 malam pada 13-14 Mei 2020, maka terjadilah tanah longsor di atas pengunungan yang mengakibatkan banjir bandang di kawasan permukiman penduduk 4 desa, dan terparah di Desa Paya Tumpi (Informasi warga Paya Tumpi, Idrus Saputra, $42^{\text {th }}$ dan M. Husen, $47^{\text {th }}, 16 / 5 / 2020$ ) 
Terapan Aksi Tanggap Daurat Model PFA pada Warga Terdampak Banjir Takengon, Aceh Tengah, 2020.

Safuwan Amin, Nur Afni Safarina, Yara Andita Anastasya, Ika Amalia

Dalam pelaksanaan kegiatan, tim PKM dosen Psikologi Unimal membagi dalam 2 sesi, yaitu sesi awal (tahap I) dan sesi lanjutan (tahap II). Pada sesi awal kegiatan difokuskan pada aksi identifikasi (assessment lapangan) dan mengalisis masalah, kemudian dilakukan pemberian bantuan pertama psikologis sesuai kode etik model PFA dijalankan secara profesional pada warga pengungsi terdampak banjir. Selanjutnya, pada sesi lanjutan, tim pengabdi melakukan evaluasi/review kebermaknaan kegiatan sesi I. Realitas aksi lanjutan ini dilakukan untuk melihat ketepatan program PFA sebagai metode penanganan pertama psikologis pada warga pengungsi pasca bencana alam.

\section{Terapan Aksi}

\section{Sesi Awal Kegiatan}

Koledoiskop kegiatan PKM tahap ini, dimana tim pengabdi yang dibantu oleh beberapa mahasiswa psikologi FK Unimal berangkat dari kota Lhokseumawe sekitar pukul 06.30 pagi bersama rombongan Aksi Relawan Kemanusiaan Universitas Malikussaleh (Unimal) Peduli Banjir Takengon yang dipimpin oleh Wakil Rektor Bidang Kemahasiswaan, dengan tetap menerapkan protokol kesehatan (karena banjir itu terjadi ditengah mencuatnya isyu wabah Covid-19). Setelah menempuh perjalanan sekitar 2,5 jam-agak sedikit lambat karena kondisi jalan ke dataran tinggi Gayo licin akibat diguyur hujan pada malam hari dan kondisi medan dengan banyak tikungan tajam terus menerobos tanjakan alam pengunungan dataran tinggi Gayo. Rombongan tim PKM psikologi Unimal baru sampai ke lokasi bekas banjir sekira pukul 09.30 WIB.

Sesampai di bekas lokasi banjir permukiman penduduk Paya Tumpi, Takengon, Aceh Tengah, rombongan tim PKM segera melapor ke posko satgas penanganan banjir Takengon yang berlokasi di SD Negeri 13 Kecamatan Kebayakan, Kabupaten Aceh Tengah, Provinsi Aceh.
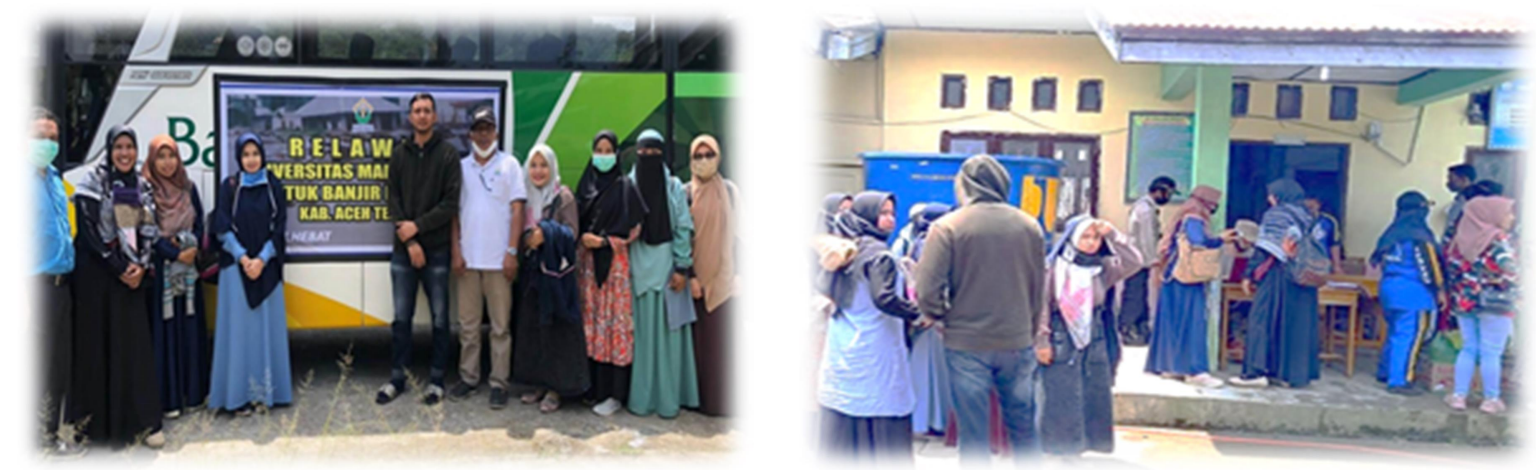

Gambar 1. Tim PKM Psi Unimal tiba di lokasi banjir (kiri), dan (kanan) Tim PKM Psi Unimal melapor ke posko banjir (Doc. PKM Psi-Unimal, 2020) 
Selanjutnya, tim PKM Psikologi Unimal menggelar briefing singkat yang dipimpin Ketua pelaksana PKM, sebelum melakukan survey umum dan assessment bersama-sama tim yang dibagi dalam 3 kelompok kerja (pokja) terkait realitas kondisi fisik lingkungan dan identifikasi realitas kebutuhan psikologis warga pengungsian, kemudian tim PKM yang dibagi dalam 3 kelompok tugas (pokja) baru bergerak menelusuri data dan informasi yang diperlukan.
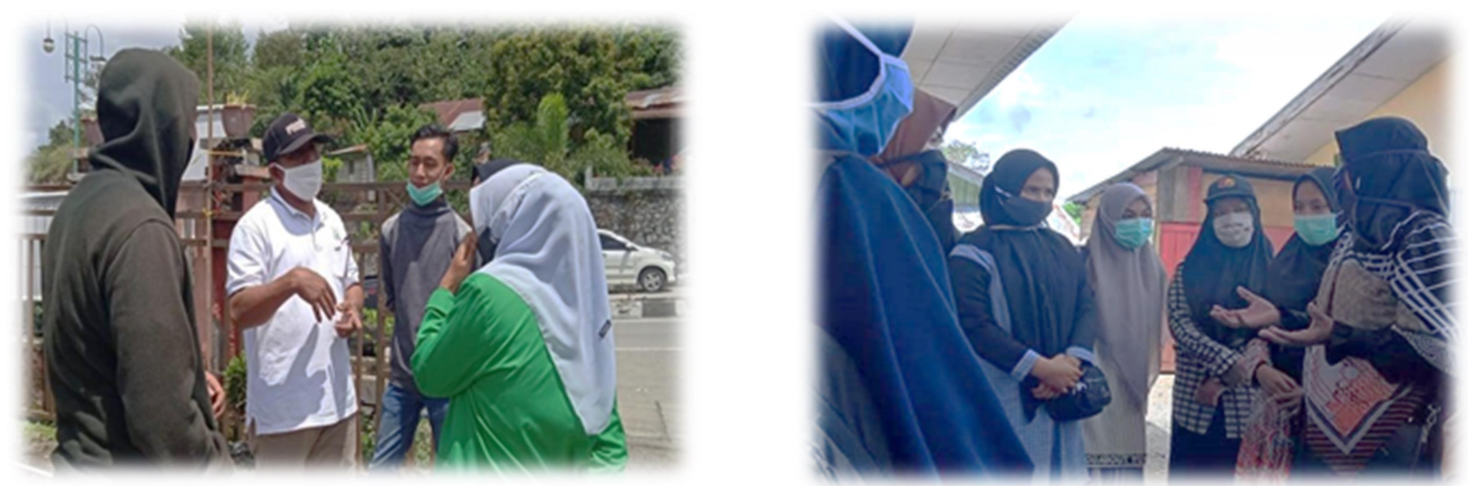

Gambar 2: Tim PKM Psikologi Unimal di briefing, sebelum melakukan tugas investigasi lapangan (Doc. PKM Psi. Unimal, 2020)

Perlu ditegaskan bahwa tim PKM psikologi Unimal menjunjung tinggi kode etik sesuai program yang difokuskan, yakni tidak pernah memaksa kehendak atau sembrono dalam melakukan kegiatan assessment pada warga terdampak banjir (para pengungsi). Secara realitas tampk bahwa para pengungsi sangat koorperatif dan mengharapkan adanya pertolongan psikologi dari relawan kemanusiaan yang mengunjungi pengungsi.


Gambar 3: Pemberian self healing pada kaum ibu (kiri) dan (kanan) berusaha membangun harapan masa depan pada anak-anak usia sekolah /anak TK (Doc. PKM Psi. Unimal, 2020)

Atas dasar inilah tim PKM psikologi Unimal baru dapat bereaksi menyalurkan program kegiatan yang telah disiapkan sebelumnya, seperti konseling umum, pemberian psiko-edukasi dan self-healing yang terfokus pada sejumlah kaum ibu, anak-anak usia sekolah dan orang tua. Kegiatan konseling umum dan psiko-edukasi menjadi penting agar wartga pengungsian tidak mampu membangun harapan dan melupakan peristiwa buruk 
Terapan Aksi Tanggap Daurat Model PFA pada Warga Terdampak Banjir Takengon, Aceh Tengah, 2020.

Safuwan Amin, Nur Afni Safarina, Yara Andita Anastasya, Ika Amalia

yang menimpa mereka sehinga mereaka bangkit kembali dengan segala aktivitas-aktivitas di realitas hidupnya. Pada anak-anak pengungsian, juga diberikan harapan/semangat hidup baru untuk menggapai cita-cita mereka. Tim PKM dosen yang dibantu oleh sejumlah mahasiswa psikologi semester akhir menggelar kegiatan pembelajaran dan hiburan pada anak-anak usia sekolah/anak TK setelah tempat bermain dan tempat tinggal mereka dengan tujuan agar anak-anak di pengungsian tidak mengingat lagi bencana banjir yang mereka alami bersama keluarganya.

\section{Kegiatan Lanjutan}

Pada tahapan ini, realisasi kegiatan dilakukan tim PKM bersama mahasiswa Psikologi Unimal dengan langkah awal melakukan survei lingkungan fisik secara menyeluruh di bekas lokasi banjir dalam rentang waktu 3,5 bulan ke depan pasca banjir medio Mei 2020. Aksi kegiatan, selain mengunjungi warga secara door to door yang dipandu oleh tokoh masyarakat setempat, bapak Idrus Saputra $\left(42^{\text {th }}\right)$ dan M. Husen $\left(47^{\text {th }}\right)$ dari pukul 9.00 pagi hari hingga menjelang petang pukul 17.30 WIB pada 14 September 2020. Kemudian pada 15 September 2020, sekitar 2,5 jam berkesempatan juga melakukan temu ramah (FGD) dengan sejumlah warga eks pengungsi banjir Takengon di balai desa Paya Tumpi.

Pada umumnya bangunan tempat tinggal eks pengungsi sudah dibangun kembali oleh pemerintah setempat dengan bantuan material bangunan dari berbagai sumbangan kemanusian dari berbagai pihak (Informasi, Idrus Saputra dan M. Husen, tokoh masyarakat setempat, 14/9/2020). Dari investigasi dan temu ramah (door to door) tim PKM Psikologi Unimal Lhokseumawe dengan warga eks-pengungsi diperoleh informasi bahwa warga pengungsian banjir Takengon sudah mulai bekerja kembali sesuai skill yang mereka punyai masing-masing. Demikian dengan anak-anak mereka sudah bersekolah lembali.
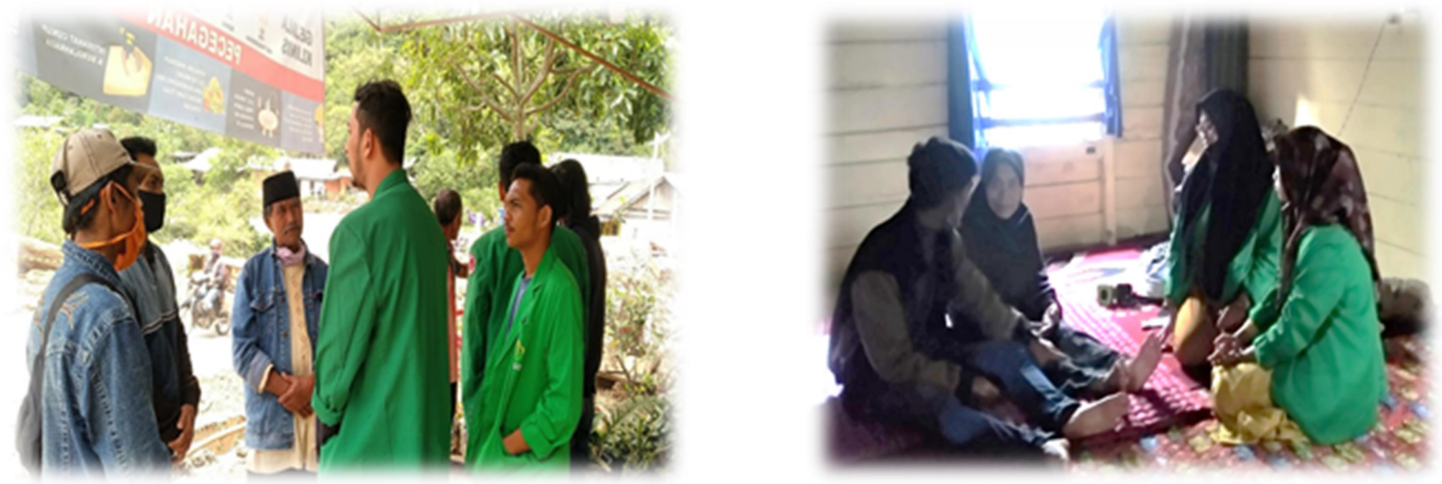

Gambar 4: Tim PKM Psikologi Unimal melakukan investigasi sesi II dengan dipandu tokoh masyarakat setempat (kiri), dan (kanan) temu ramah dalam evaluasi program PFA (Doc. PKM Psi. Unimal, 2020) 
Di sisi lain, warga eks-pengungsi banjir juga mengungkapkan rasa terima kasih pada tim PKM Psikologi Unimal yang menurut mereka memiliki arti penting dengan kehadiran tim PKM pasca banjir medio Mei 2020 lalu. "Kami sangat berterima kasih pada bapak-ibu dan adek mahasiswa dari Unimal Lhokseumawe karena telah menghibur dan menemani kami di saat kami di pengungsian dulu" (Ungkapan hati, seorang ibu rumah tangga, Nek Rukiyah, $65^{\text {th }}$, warga Desa Paya Tumpi, dalam suasana temu ramah di balai desa setempat, $15 / 9 / 2020)$.
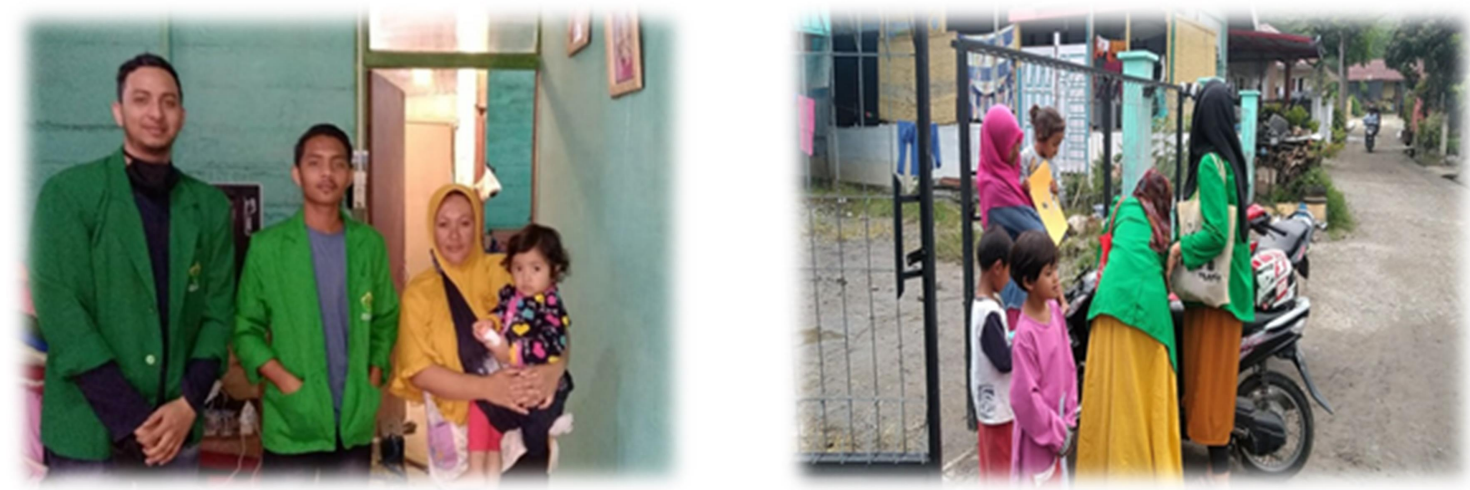

Gambar 5: Tim PKM Psi. Unimal menyapa warga dan anak-anak TK secara door to door pada sesi II (Doc. PKM Psi. Unimal, 2020)

Ungkapan senada juga disampaikan warga lainnya, seorang ibu rumah tangga yang kehilangan rumahnya saat banjir bandang terjadi. "Kami sangat senang kehadiran bapakibu pada waktu itu, menjenguk kami di kala susah. Kami bersyukur ada yang peduli pada kami”. (Ungkap, Mardiati, 38 ${ }^{\text {th }}$, di akhir acara temu ramah dengan warga eks-pengusi banjir Takengon, 15/9/2020. Berdasarkan realitas kegiatan ini, tim PKM menyimpulkan bahwa terapan aksi tanggap darurat dengan model PFA menjadi bermakna bagi warga pasca bencana jika ada tindak lanjut tahapan ke dua dari kegiatan awal yang dilakukan. Sebaliknya, jika tidak ada tindak lanjut, kegiatan akan menjadi kurang bermakna dan tidak diketahui tepat sasaran atau tidak.

\section{SIMPULAN DAN SARAN}

Pendekatan Psychological First Aid (PFA) relevan diterapkan dalam situasi darurat (pasca bencana) pada individu/komunitas, dengan catatan menjunjung tinggi aturan main operasionalnya, yang paling penting adalah tidak memaksa kehendak relawan (kemanusiaan) di lapangan. Selain itu, juga perlu dipertimbangkan metode yang akan diterapkan di lapangan, serta berkoordinasi dengan pelbagai pihak. Tanpa dukungan positif dari warga permukiman terdampak banjir dan pemerintah daerah setempat, kegiatan dipastikan tidak akan berjalan efektif. 
Cuplikan kegiatan PKM tim dosen dan beberapa mahasiswa Psikologi FK Universitas Malikussaleh (Unimal) Lhokseumawe, Aceh dalam kegiatan ini membuktikan bahwa pertolongan pertama psikologis (PFA) dilakukan setelah dilakukan survei dan investigasi kondisi lapangan secara menyeluruh. Lebih dari itu, metode operasional yang diterapkan sejatinya sangat menentukan kesuksesan program PKM. Dalam aktivitas ini metode operasional dirancang dalam dua sesi kegiatan; inversitgasi (assessment) dan tahap aksi tanggap darurat dengan model PFA dipandang efektif dan berjalan sesuai program yang telah dipersiapkan sebelumnya. Selain itu, juga

\section{UCAPAN TERIMA KASIH}

Seluruh tim pelaksana PKM Psikologi FK Unimal Lhokseumawe, Aceh mengucapkan terima kasih banyak kepada semua pihak, baik Universitas Malikussaleh yang telah mendukung biaya operasional kegiatan, maupun kepada masyarakat daratan tinggi Gayo, Aceh Tengah dan pemerintah daerah setempat yang telah mendukung dan memfasilitasi kegiatan pengabdian ini, sehingga terlaksana dengan baik sesuai jadwal yang direncanakan.

\section{DAFTAR PUSTAKA}

Al Hamidy, H. Bahrun (2020). Psychological First Aid Dalam Bencana Pandemi Covid19.https://kumparan.com/habibah-psikologi/psychological-first-aid-dalam-bencanapandemi-covid-19-1tReB1gGuNu/full

Safitri, N., \& Khairat, I. 2017. Konseling trauma oleh Ikatan Konselor Indonesia (IKI) untuk korban bencana alam gempa bumi (studi di Kabupaten Pidie Jaya). In Ifdil, I., Bolo Rangka, I., \& Adiputra, S. (Eds). Seminar \& Workshop Nasional Bimbingan dan Konseling: Jambore Konseling 3 (pp.74-84). Pontianak: Ikatan Konselor Indonesia (IKI).

Kementerian Pemberdayaan Perempuan dan Perlindungan Anak (2020). Buku Panduan Dukungan Psikososial bagi Anak Korban Bencana Alam. https://www.kemenpppa.go.id/index.php/page/read/38/2713/buku-panduandukungan-psikososial-bagi-anak-korban-bencana-alam

Margaretha \& Dita Kencana Sari (2020). Pertolongan Psikologis Pertama: Panduan Bagi Relawan, Surabaya: Airlangga University Press. https://apps.who.int/iris/ bitstream/handle/10665/44615/9789241548205-ind.pdf

Safuwan, dkk (2020). Survvei dan assesment kebutuhan psikologis pengungsi banjir Takengon. Aceh Tengah. Prodi Psikologi FK Universitas Malikussaleh (16/5/2020)

Yuwanto, L., Adi, C. M. P., Pamudji, S. S., \& Santoso, M. (2014). Issue kontemporer psikologi bencana. Sidoarjo : Dwiputra Pustaka Jaya. 